\title{
El contexto de la decisión judicial y su especial importancia a la hora de fallar por equidad
}

\author{
Judicial decision's context and its special importance when deciding \\ in equity or ex aequo et bono
}

\author{
Valentina Rivadavia \\ Universidad de la República \\ ORCID: 0000-0002-6089-0506 \\ Correo: valentinarivadavia@gmail.com \\ Recibido: 20/04/2021 \\ Aceptado: 02/05/2021
}

\section{Resumen:}

El objeto de estas líneas consiste en plasmar algunas consideraciones acerca de las condiciones de contexto éticas y normativas que deberían darse para que los tribunales pudieran fallar haciendo uso de principios, puntualmente, el de equidad, para resolver las cuestiones sometidas a su consideración. Se analizará cómo la equidad presenta particularidades que dotan de especial relevancia a las condiciones normativas y éticas de la función jurisdiccional a efectos de asegurar que la decisión judicial cuente con un mínimo de racionalidad instrumental. Se utilizará como principal guía el análisis elaborado por Jesús Vega que estudia críticamente las visiones de equidad delineadas por Ferrajoli y Aristóteles.

Palabras clave: ética judicial; decisión judicial; equidad; contexto de la decisión.

\begin{abstract}
:
The purpose of this work is about some considerations made about the ethical and normative context conditions that should be present in order to courts could decide grounding their decisions on principles, specifically that of equity, to resolve issues submitted for their consideration. Through this article, it will be analyzed how equity presents several particular characteristics that bear and provide special relevance to the normative and ethical conditions of the jurisdictional function in order to ensure that the judicial aware reckon with a minimum of instrumental rationality. The analysis and work prepared by Jesús Vega, who critically studies the visions of equity outlined by Ferrajoli and Aristóteles, will be used as the main guide (work tool).
\end{abstract}

Keywords: judicial ethics; judicial decision; equity; context of the decision. 


\section{Planteo del problema}

Es común observar que la configuración del contexto (sea cual fuere su naturaleza: ética, institucional, moral, etc.) no es indiferente a la hora de comprender el significado de las acciones y en especial de sus consecuencias. Así, para comprender el significado de la acción de contratar no da igual que estemos ante un contexto de violencia que ante uno de libertad de elección, como tampoco da igual que estemos ante un contexto normativo constitutivo (donde existen normas que constituyen acciones) o ante un contexto normativo regulativo (Atienza y Ruiz Mantero, 2007, p. 23).

De igual modo, tomar decisiones por parte de los jueces supone contar con ciertas condiciones y facultades que viabilicen la producción de los resultados y consecuencias deseados.

En este escenario, la configuración del contexto en que se inserta la actividad jurisdiccional puede presentarse por un lado como (1) el análisis del conjunto de condiciones normativas (de organización institucional y funcional) que han de estar presentes para que los órganos jurisdiccionales puedan operar, y, (2) por otro lado, el análisis del conjunto de condiciones éticas (ética jurídica) con las que se debe contar para que los tribunales puedan argumentar y justificar sus decisiones con arreglo a determinados finales: lograr decisiones justas y racionales.

A su vez, la tarea argumentativa que desarrollan los tribunales supone en algunos casos el uso de principios como parámetros normativos para la imputación de consecuencias a las acciones sobre las que deben emitir un pronunciamiento. Aquí, la equidad como principio presenta ciertas particularidades que merecen hacer especial hincapié en la importancia de las condiciones normativas y éticas de la función judicial, de forma que con ello se asegure un mínimo de racionalidad instrumental y de fines (González Lagier, 2013, p. 154) para juzgar racionalmente.

\section{Sobre la equidad y su carácter de principio}

Sabemos que la equidad es un principio que integra el derecho; un estándar que utilizamos para inspirar la construcción de normas y para resolver litigios. Ahora bien, la equidad se vincula también y muy especialmente con la ética judicial, en la medida que ésta hace al contexto de decisión judicial. 
La noción de equidad, al menos en la que me basaré para efectuar el presente análisis, "se remonta a la vieja idea aristotélica de la epieikeia como «corrección de la ley» de Aristóteles expuesta en la Ética a Nicómaco y en la Retórica” (Vega, 2013, p. 234). Aristóteles construye el análisis sobre la equidad a partir de la idea básica de que:

Muchas propiedades del caso juzgado no hallan encaje en el marco abstracto y genérico de la norma [...] De ellas no puede predicarse en consecuencia la verdad jurídica. La ley no puede prever todas las connotaciones posibles de los hechos por ella denotados. Estas tienen que ser individualizadas y comprendidas en su concreción particular en cada caso, y eso es la equidad: el poder de connotación del juez (Vega, 2013, p. 241).

Por tanto, la equidad viene a poner al descubierto una realidad, resistida y en algunos casos negada por algunos operadores del derecho:

Que las situaciones de la práctica desbordan toda norma preexistente mediante la cual pretenden ser gobernadas, desafiando así a la práctica de aplicación... a llevar a cabo una labor interpretativa de índole constructiva (y en los "casos difíciles", a poner en cuestión la norma misma) (Vega, 2013, p. 241).

Aristóteles habla de la jurisdicción como un poder que exige introducir la idea de práctica a efectos de comprender la vinculación legislador-juez como el vínculo entre dos prácticas institucionales diferentes pero coordinadas: la práctica de legislar y la práctica de aplicar la ley. Ambas prácticas, legislación y jurisdicción:

Son además prácticas "de segundo grado", es decir, se construyen sobre las prácticas sociales ordinarias de primer grado (externas al aparato institucional jurídico) respecto de las cuales tanto legisladores como jueces actúan a la luz de ciertos fines y valores envolventes del derecho (Vega, 2013, p. 246).

Por tanto, ambas prácticas responden a una práctica colectiva "más amplia de naturaleza esencialmente política: el proceso de la construcción del Estado, de la organización política de una sociedad, proceso que se considera dirigido en función de 
ciertos valores o principios fundamentales: aquellos que están plasmados en la constitución" (Vega, 2013, p. 246).

Así, "La legislación es una institución que persigue la implantación de ciertos valores en la esfera de la práctica social en función del marco constitucional respectivo" (Vega, 2013, p. 248). Pero las leyes no son suficientes:

Es preciso además asegurar que los valores que ellas promueven se vean materializados en todas y cada una de las situaciones que esas normas contemplan. Esa es la razón de ser de la jurisdicción: producir una sucesión de decisiones singulares y recurrentes en aplicación de las reglas legislativas que conduzcan a verificar aquellos balances de valores que las justifican (Vega, 2013, p. 248).

Claramente, la tesis que respalda el modelo aristotélico habla de una jurisdicción como una empresa deliberativa de consistencia esencialmente valorativa. Explica el autor que:

Las decisiones judiciales sólo pueden responder a los balances de valores expresados en las reglas legislativas que son precisamente aquellos que el legislador pretende transportar a las prácticas sociales por la mediación de tales reglas y, por tanto, por la mediación de los jueces, quienes tienen por misión hacerlos presentes en dichas prácticas (Vega, 2013, p. 251).

La motivación o argumentación judicial, entonces, es una práctica comprometida con esos valores, y tiene igualmente un carácter interpretativo, pues está valorativamente involucrada.

Asimismo, la verdad que rige la motivación y argumentación fáctica no es una práctica exenta de valoración, no encaja en el molde de los hechos formalmente construidos a imagen y semejanza de la ciencia o la técnica.

En tal sentido, ello sucede porque la prueba no versa sobre hechos observables directamente por el juez, sino sobre la reconstrucción de eventos prácticos acaecidos en el pasado que se introducen en el proceso a través de proposiciones sobre hechos. En este sentido:

La interpretación judicial de los hechos no se detiene en la búsqueda de la verdad fáctica ni persigue ésta por sí misma -no es una empresa teórica- 
sino que obedece al fin primordial de establecer una decisión que ponga término al conflicto cuya justificación va a presumirse autoritativamente como verdadera (res iudicata pro veritate habetur). Es decir, se trata de una verdad como corrección práctica (Vega, 2013, p. 254).

Por tanto, la verdad es una condición necesaria de la justicia pero no suficiente, lo que nos lleva a que no puede ser vista como una garantía epistémica que sirva por sí sola para neutralizar las valoraciones del juez, ni mucho menos como criterio exclusivo de corrección práctica.
Aunque el margen de elección subjetiva entre hipótesis probatorias se haya reducido hasta un grado máximo (pensemos en pruebas de ADN en el ámbito civil o penal), el juez sigue teniendo que adoptar una decisión práctica (prudencial). Debe construir el juicio de imputación (la individualización de la culpabilidad) que es, primero, estrictamente un juicio de valor (en tanto consiste en la atribución de una desviación normativa) y, segundo, un juicio de valor indeducible de ese razonamiento teórico: sólo se sustenta en una toma de posición del juez con base en las normas jurídicas cuyos valores subyacentes (los bienes jurídicos en este caso) pretende hacer imperar en el caso mediante una deliberación específica (Vega, 2013, p. 255).

Así como la verdad es un valor que no puede ser establecido por adelantado de forma general en una norma, sino sólo por el razonamiento judicial singularizado en cada caso, pasa lo mismo con la justicia, siendo ésta la idea de fondo de la equidad aristotélica.

Según Aristóteles no es posible establecer lo justo en términos universales ya que la justicia es un valor práctico (no teórico). Es de ahí que deriva la textura abierta o la indeterminación de las reglas jurídicas -en contraposición de las reglas teóricas del conocimiento regidas por el valor de verdad-que:

Están mediadas por valores prácticos como los que tienen que ver con la justicia, que son relativos a la acción de otros sujetos (pros heteron) y que tienen que ser salvaguardados y amparados por la decisión en primera persona del juez, que es su "personificación” y "guardián", o sea, su garante. De manera que la corrección de una regla práctica -incluso cuando ha sido correctamente deliberada en la instancia legislativa- sólo 
puede ser asegurada a posteriori, mediante un discurso específico de aplicación que determine cómo ha de ser correctamente aplicada a la situación dada, incluyendo la posibilidad de que sea abandonada para dar lugar a una nueva regla. Esta es la única forma en que la universalidad lógica (el juego de lo general-particular) puede ser un criterio de racionalidad apropiado también en la esfera de la praxis (Vega, 2013, p. 256).

En síntesis, Aristóteles viene a poner sobre la mesa una realidad que como magistrados enfrentamos a diario:

La denotación judicial, la subsunción o calificación jurídica, no depende entonces centralmente de ningún procedimiento "lógico-lingüístico" de naturaleza algorítmica (en el sentido de una derivación de lo general a lo particular, de la inclusión "mecánica" del caso específico en el caso genérico), sino de un juicio evaluativo acerca de la corrección o incorrección en cada caso de dicha subsunción o clasificación de los hechos bajo la connotación de la regla o término legal de que se trate (Vega, 2013, p. 257).

El criterio del juez no podrá ser otro que el de:

Los valores o balances de valores que justifican la propia regla y en términos de los cuales se formulan los predicados fácticos de sus antecedentes y las consecuencias jurídicas correspondientes (esto es, la planificación de la coacción estatal en sentido amplio). Si esos valores se ven satisfechos, preservados o realizados en el caso en cuestión (que es, recordemos, la finalidad última perseguida por la legislación y la razón de ser de la propia jurisdicción) a la vista de las consecuencias prácticas que la aplicación de la regla supondría, entonces está justificada tal aplicación (Vega, 2013, p. 258).

Desde este enfoque, los casos fáciles serán aquellos en que tiene cabida una interpretación convencional, donde el juez aplica la norma al caso concreto y se preserva la continuidad axiológica con los propósitos del legislador: es decir, la coherencia. Pero, si de dicha aplicación, el valor que la regla pretende promover resulta frustrado o defraudado en el caso, entonces deberá apartarse de la regla, modificarla 
interpretativamente: "es la equidad como corrección de la ley de la que nos habla Aristóteles, que implica introducir excepciones a las reglas a la luz de los casos y, por tanto, apartarse de la interpretación literal" (Vega, 2013, p. 258).

Aristóteles nos plantea un concepto pragmático de las reglas jurídicas, en el que la relación de las mismas con el caso concreto se da por la mediación de los valores que las justifican.

La equidad aristotélica no niega la idea de generalidad que es consustancial a la idea de regla. Como vimos, Aristóteles vincula la justicia política a la igualdad y esta (junto con la "sabiduría de los muchos" de la democracia) es la razón por la que las leyes tienen que ser universales (katholou) (Vega, 2013, p. 258).

En efecto, en la teoría aristotélica:

La equidad es la "justicia que va más allá de la formulación de la regla [to para ton gegrammenon nomon dikaion]", que corrige "el error que resulta de su carácter universal" (1137b, 24-27). Esa dimensión valorativa es precisamente lo que hace de la equidad un tipo de justicia "mejor" (beltion) y "superior" (kreitton) respecto de la justicia legal (nomikon dikaion), pero ello no supone que deje de ser universalizable y de plasmarse a su vez en reglas prácticas, lejos de toda justicia sustancial de carácter "particularista" (Vega, 2013, p. 259).

En este sentido, "el razonamiento práctico del juez puede quedar desvinculado de la formulación literal de las reglas del legislador, pero no desvinculado de la coherencia axiológica con el razonamiento práctico del legislador, a través del caso y la regla concernida" (Vega, 2013, p. 259). Digamos que la razón de la corrección equitativa consiste en que el propio legislador habría corregido la regla de tener que aplicarla al caso concreto en estudio. En síntesis:

La tesis aristotélica de la equidad sienta así las bases de la interpretación jurídica como la labor constructiva y racional-deliberativa (prudencial) consistente en reconocer y confirmar pero también ampliar y restringir el alcance de las reglas legislativas como parte de la práctica de su aplicación (Vega, 2013, p. 260). 


\section{Sobre el contexto institucional-normativo}

Entonces, ya vimos que la práctica judicial es esencialmente valorativa y que dicha valoración que hace el juez se encuentra guiada o respaldada por los valores que persigue una sociedad en determinado momento histórico. Por tanto, la valoración -en términos aristotélicos- debe ser coherente con los valores o balances de valores que justifican la propia regla.

De ahí deriva la importancia del contexto institucional-normativo en el que se inserta el juez, principalmente cuando debe fallar por equidad. Dicho de otra forma, resulta fundamental asegurar ciertas condiciones institucionales y normativas especialmente cuando el juez falla por equidad a efectos de asegurarnos que su valoración efectivamente esté inspirada en los valores que respaldan al derecho y no en otros, como podrían ser valores individuales.

Así, desde el punto de vista institucional podemos observar la presencia de las siguientes pautas o reglas que regulan el quehacer judicial, y que operan, a mi criterio, como insumos positivos para facilitar la tarea valorativa de los jueces en aplicación de la equidad y su consecuente contralor:

- Las reglas que regulan el acceso al poder judicial: procuran asegurar ciertos niveles de formación práctica y académica de parte de los jueces, de modo de asegurar un mínimo nivel intelectual de entendimiento y decisión que será fundamental para la toma de resoluciones que involucren el principio de equidad.

- Las reglas que regulan el ascenso de los jueces: en la medida que se sustentan en variables imparciales y éticamente positivas, comportan un gran elemento para garantizar la toma de decisiones por equidad. Algunas de estas variables son: los méritos académicos, la evaluación por informes de los superiores procesales, el ejercicio de docencia jurídica a nivel universitario, la participación los cursos del CEJA, los informes elaborados por el Colegio de Abogados del Uruguay y demás parámetros establecidos en el artículo 2 inciso segundo y tercero de la Acordada 7772.

- El ejercicio reglado, ponderativo y ordenado de la función, que aunque muchas veces se ve afectado por la sobrecarga de trabajo, en términos ideales 
confiere a los magistrados las condiciones necesarias para adoptar decisiones.

- La existencia de reglas como la autonomía técnica que permiten a los jueces fallar según su leal saber y entender, haciendo confianza en la plenitud de la capacidad intelectual del juez como agente moral autónomo.

Estas reglas han de verse además en conjunción con las condiciones normativas e institucionales no aplicables a la judicatura como órgano de decisión, pero sí a cuerpos afines que interactúan con aquella, en el proceso de toma de decisiones. Un ejemplo de ello es el cuerpo pericial, en cuyo caso concretamente, sería deseable que existiesen comunidades expertas, estudios empíricos de aquellos temas que son objeto de decisión, entre otros, de forma que se potenciara la racionalidad en la toma de decisiones por parte de los jueces.

\section{Sobre el contexto ético}

\section{Amaya expresa que:}

La ética jurídica es un área específica, dentro del campo de la ética, que tiene por objeto la reflexión acerca de cuáles son los estándares morales que deben guiar la conducta de los agentes jurídicos en el ejercicio de su profesión. La ética jurídica es un área especial dentro, la ética profesional, la cual es, a su vez, una subdisciplina de la ética aplicada (Amaya, 2009, p. $8)$.

En línea con lo expuesto, es evidente que el juez debe cumplir con ciertas condiciones éticas para ejercer su cargo, condiciones éticas para fallar:

En el Estado de Derecho al juez se le exige que se esfuerce por encontrar la solución justa y conforme al Derecho para el caso jurídico que está bajo su competencia, y que ese poder e imperium que ejerce procede de la misma sociedad que, a través de los mecanismos constitucionales establecidos, lo escoge para tan trascendente y necesaria función social, con base en haber acreditado ciertas idoneidades específicas. El poder que se confiere a cada juez trae consigo determinadas exigencias que serían inapropiadas para el ciudadano común que ejerce poderes privados; la aceptación de la función 
judicial lleva consigo beneficios y ventajas, pero también cargas y desventajas. Desde esa perspectiva de una sociedad mandante se comprende que el juez no sólo debe preocuparse por ser, según la dignidad propia del poder conferido, sino también por parecer, de manera de no suscitar legítimas dudas en la sociedad acerca del modo en el que se cumple el servicio judicial (Código Iberoamericano de Ética Judicial, Exposición de motivos, p. 3).

La importancia del parecer en el juez, se ve expuesto con gran evidencia cuando se deben tomar decisiones basadas en principios (estándares normativos esencialmente amorfos o imprecisos), pues allí importa cuidar con mucho celo el no revelar ni reflejar sus principios o componentes valorativos personales y, en su lugar, otorgar prioridad a los valores y principios contenidos en la legislación que debe aplicar.

Ahora bien, desde el punto de vista metodológico es posible distinguir, en el marco del contexto ético, según estemos ante (A) condiciones éticas concernientes a la vida personal del juez, que guardan relación con su comportamiento privado y (B) condiciones éticas que atañen al juez actuando en el ejercicio de su función, donde es posible encontrar un mínimo común denominador de condiciones éticas para todos los jueces. Un ejemplo de ello es el saludo entre colegas conocidos o vinculados en base a una relación extra-profesional. Claramente, no saludarse con un beso comporta una condición ética de comportamiento positiva, en la medida que evita generar un impacto negativo en la comunidad de operadores del derecho.

A su vez, entre las condiciones éticas aplicables a todos los jueces en ejercicio de sus funciones, también es posible reconocer la existencia de condiciones éticas para (A) el juez actuando de forma individual, y condiciones éticas (B) de los jueces actuando en forma colegiada.

El buen ejercicio de los jueces que actúan en tribunales colegiados implica, por ejemplo, el ejercicio de una correcta y eficaz deliberación de los asuntos jurídicos, lo que ha sido catalogado por algunos teóricos del derecho como una virtud: la conocida virtud deliberativa. En esos casos (los tribunales colegiados), cuando no se da la deliberación correspondiente, falta una condición ética esencial para el ejercicio de la judicatura (por todos, véase Amaya). 


\section{Conclusiones preliminares}

Lo antedicho permite reparar en las siguientes consideraciones relativas al contexto de la decisión judicial y su especial importancia a la hora de fallar por equidad:

- La equidad es un principio que supone la adopción de una actitud específica a la hora de tomar decisiones que supongan un ajuste normativo al caso concreto planteado.

- Trabajar con principios implica tomar decisiones prácticas, y para eso es necesario que se verifiquen ciertas circunstancias de contexto.

- Si yo debo tomar la decisión de darle una indemnización a un trabajador basándome para ello en el principio de igualdad (invocado por las partes), podré notar que dicho principio me resulta útil tanto para fundar una decisión negativa hacia dicha pretensión como para fundar una decisión positiva. No obstante, lo que es evidente y no admite resultados tan dispares es que la decisión que tome no puede estar incentivada por un estímulo personal, ej. un ascenso en la carrera. Por eso el contexto institucional en el que el juez decide es fundamental para llegar a decisiones fundadas en lo normativo y no en otras consideraciones.

- De igual forma se comportan las condiciones éticas individuales privadas e individuales profesionales, y también las colectivas, en la medida que propician condiciones ideales para la toma de decisiones.

- Por su parte, es relevante notar también que el contexto es particularmente importante para la toma de decisiones que involucren la equidad, pues allí la complejidad es mayor debido a dos cuestiones: por un lado el propio concepto de principio como estándar normativo es vago, amorfo o impreciso y requiere que se concrete para el caso concreto y; por otro lado sumado a este problema propio de los principios, el hecho de que estemos ante uno vinculado al concepto de equidad, un concepto polisémico, centralmente vago. 


\section{Referencias}

Amaya Navarro, M. A. (2009). Virtudes judiciales y argumentación. Una aproximación a la ética jurídica. México: Tribunal Electoral del Poder Judicial de la Federación

Atienza, M. \& Ruiz Manero, J. (2007). Las piezas del Derecho. Teoría de los enunciados jurídicos. Barcelona: Ariel.

Código Iberoamericano de Ética Judicial (CIEJ) aprobado en la XVII Reunión Plenaria de la Cumbre Judicial Iberoamericana el 2 de abril de 2014.

González Lagier, D. (2013). Quaestio facti. Ensayos sobre prueba, causalidad y acción. México: Fontamara.

Vega, J. (2013). La equidad según Ferrajoli y la equidad según Aristóteles: una comparación crítica. Doxa. Cuadernos de Filosofía del Derecho, 0(36), 229-273. doi: https://doi.org/10.14198/DOXA2013.36.11

\section{Contribución autoral}

a) Concepción y diseño del trabajo; b) Adquisición de datos; c) Análisis e interpretación de datos; d) Redacción del manuscrito; e) revisión crítica del manuscrito.

V. R. ha contribuido en a, b, c, d, e.

Editor científico responsable: Dra. María Paula Garat. 